\title{
Application of plasma nitriding on low-alloy (50CrV4+QT) steel in order to improve its fatigue resistance
}

\author{
M. Kuffová ${ }^{*}$, P. Čelko² \\ ${ }^{1}$ Academy of the Armed Forces of Gen. M. R. Stefánik, Department of Mechanical Engineering, \\ Demänová 393, 03101 Liptovský Mikuláš, Slovak Republic \\ ${ }^{2}$ Alexander Dubček University of Trenčin, Faculty of Special Technology, \\ Pri parku 19, 91106 Trenčín - Záblatie, Slovak Republic
}

Received 11 November 2014, received in revised form 14 May 2015, accepted 29 June 2015

\begin{abstract}
The presented work is focused on the fatigue endurance improvement by using plasma nitriding. In this research the microstructure and fatigue properties of low-alloyed steel $50 \mathrm{CrV} 4+\mathrm{QT}$ were evaluated. The low-alloyed (manganese-chromium-vanadium) steel is commonly used after heat treatment - quenching and tempering - QT(.7). This steel is widely used for highly loaded machines and parts of road vehicles: crankshafts of diesel engines, shafts of driving gears, connecting shafts, pins, springs, axle shafts and piston rods. Steel is suitable for quenching and tempering and contains chemical elements which predetermine it to the chemical-thermal treatment: plasma nitriding. The fatigue limit was determined at the rotating beam fatigue. The fatigue limit improvement at $1 \times 10^{7}$ cycles was $44 \%$. Explanation of the improvement is based on stabilized gradient of properties in treated layer.
\end{abstract}

K e y w o r d s: plasma nitriding, low-alloy steel $50 \mathrm{CrV} 4$, rotating beam fatigue tests, fatigue endurance

\section{Introduction}

Nitriding is a very effective method to increase the lifetime of construction materials and tools by improving material properties, e.g. enhancing surface hardness, improving wear resistance (abrasive, adhesive, erosive, cavitation), reducing a friction coefficient, increasing a fatigue limit or corrosion resistance. As a result, the nitriding process develops nitrides of iron in the diffusion layer inside the nitride material [1].

The use of nitriding steels, which include appropriate elements to form nitrides is generally recommended for the nitriding process. The main elements that cause an increase in the hardness of the nitride diffusion layer are mainly molybdenum, vanadium, aluminium or chrome. Nitriding is usually applied to the heat-treated material, i.e. after the chemical-thermal processing [2-4].

Nitriding process can be divided into 3 groups in accordance with scope:

1. nitriding aiming to increase the surface hardness,
2. nitriding aiming to increase the fatigue limit,

3. nitriding aiming to increase the corrosion resistance.

When common nitriding methods are used, the surface of alloyed steels is intensely saturated during the whole process at the hypoeutectoid temperature. During the saturation of the solid solution $\alpha$, there is a concentration gradient of nitrogen between saturated surface and diffusion interface. There is also a concentration gradient of alloying elements between the core and the diffusion interface. The nitriding layer growth is carried out by the diffusion interface transfer from the surface towards the core. Local nitrogen loss caused by the precipitation is systematically substituted by absorption of more nitrogen.

The nitriding layer thickness usually ranges from 0.2 to $0.6 \mathrm{~mm}$ for construction elements. With respect to the fatigue resistance increase at the rotating beam fatigue, the prediction is that sufficient layer thickness is 0.1 to $0.2 \mathrm{~mm}$. With respect to the high specific pressure transfer, higher thickness $(0.4$ to $0.5 \mathrm{~mm})$ is

*Corresponding author: tel.: +421 905413 917; e-mail address: $\underline{\text { mariana.kuffova@aos.sk }}$ 


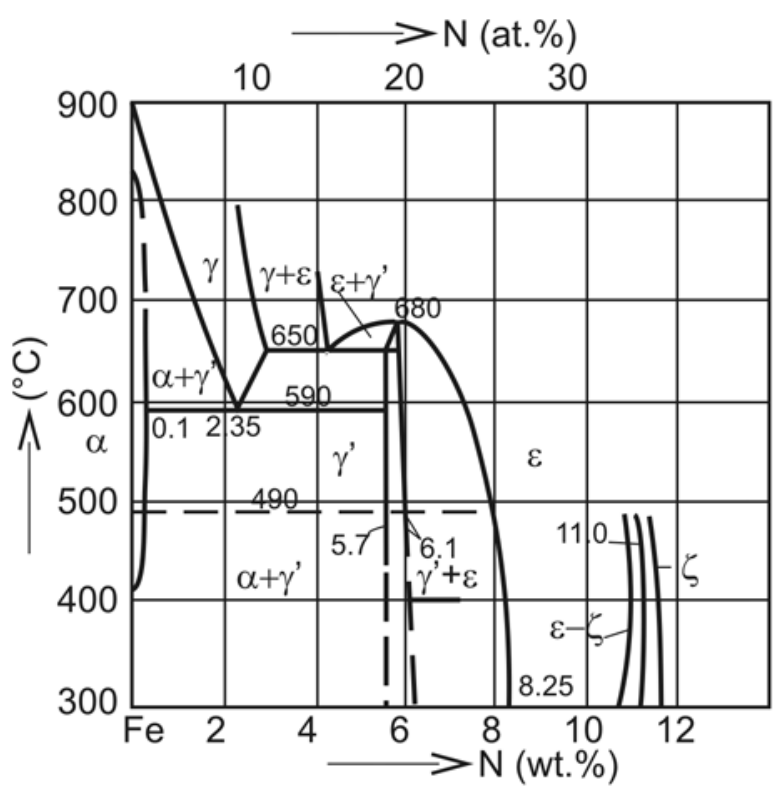

Fig. 1. Binary phase diagram $\mathrm{Fe}-\mathrm{Fe}_{2} \mathrm{~N}[1]$.

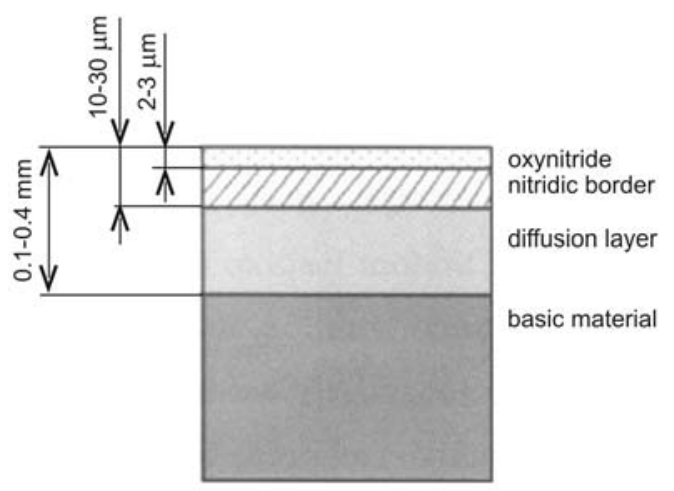

Fig. 2. Nitride layer structure [5].

recommended. On the other hand, the higher the nitriding layer thickness, the lower is impact strength [5].

\section{Nitride layer composition}

Nitride layer structure is formed in accordance with binary phase diagram $\mathrm{Fe}-\mathrm{N}$, partially depicted in Fig. 1. Nitride layer is created (Fig. 2) [1]:

- $\alpha$-phase $-\mathrm{Fe}_{\alpha}(\mathrm{N})$ solid solution of nitrogen containing max. $0.1 \% \mathrm{~N}$ at an eutectoid temperature with body centred cubic structure [1].

- $\varepsilon$ labelled $\mathrm{Fe}_{2-3} \mathrm{~N}$ which is stable at temperatures lower than $670^{\circ} \mathrm{C}$, provided higher nitrogen content. Iron atoms in it occupy the nodes of a hexagonal close packed structure; nitrogen then takes a variable part of the interstitial positions. Nitride $\varepsilon$ appears in

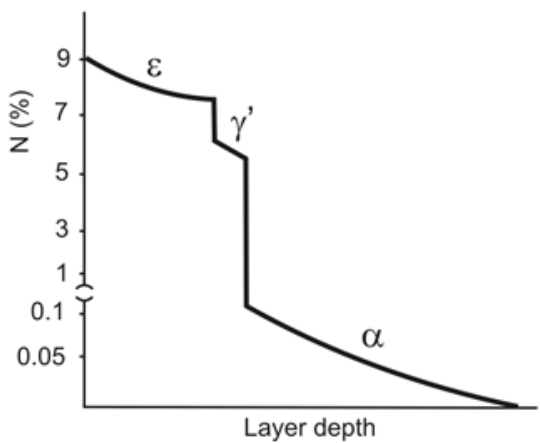

Fig. 3. Phases of nitride layer [5].

a wide range of nitrogen content $(4.35-11$ wt. $\% \mathrm{~N}$ at $670^{\circ} \mathrm{C}$ ), but its composition varies radically depending on temperature. It has developed very intensely for temperatures $450-550{ }^{\circ} \mathrm{C}$. At the beginning it creates $\mathrm{V}$-formations that in the side face growth foul each other. The further growth is possible only in the direction of the concentration gradient [1].

In the structure of the nitride layer, there can also be formed:

- $\gamma^{\prime}$-phase formed by $\mathrm{Fe}_{4} \mathrm{~N}$ containing the lowest amount of nitrogen. $\gamma^{\prime}$ is formed in face centred cubic structure and contains $5.3-5.75 \% \mathrm{~N}$. It has susceptibility to form needles on the V-shaped $\mathrm{Fe}_{3} \mathrm{~N}$.

- $\gamma$-phase - solid nitrogen solution $\mathrm{Fe}_{\gamma}(\mathrm{N})$ with a face centred cubic structure with percentage $2.35 \% \mathrm{~N}$ at eutectoid temperature.

- $\xi$-phase formed by $\mathrm{Fe}_{2} \mathrm{~N}$ with orthorhombic structure and percentage 11.1 to $11.3 \% \mathrm{~N}$. The nitride is stable up to $490^{\circ} \mathrm{C}$.

- $\alpha^{\prime \prime}$-phase - nitride $\mathrm{Fe}_{16} \mathrm{~N}_{2}$; it is not implied in binary phase diagram. It can be formed on the saturated iron surface at the temperature range $450-500^{\circ} \mathrm{C}$. In this case, a particle size is 10 to 15 times higher than a precipitate size formed into grains after tempering of oversaturated solid solutions $\mathrm{Fe}_{\alpha}(\mathrm{N})$ and $\mathrm{Fe}_{\gamma}(\mathrm{N})$ $[1,2]$.

Phases of the nitride layer are shown in Fig. 3.

\section{Plasma nitriding}

Plasma nitriding principle is based on the direct ionization of nitrogen. The treated material is stored in a vacuum container (recipient) where the container is connected as an anode while nitride components as a cathode. The largest voltage drop occurs in few millimetres from the surface of the component, this fact appears as light emitting anomalous discharge glow (Fig. 4). Due to a strong electric field (DC - voltage 400-1000 V) between the recipient body and the component surface ionization of a gas or mixture of gases occurred, e.g. nitrogen and hydrogen. Positive ions are 


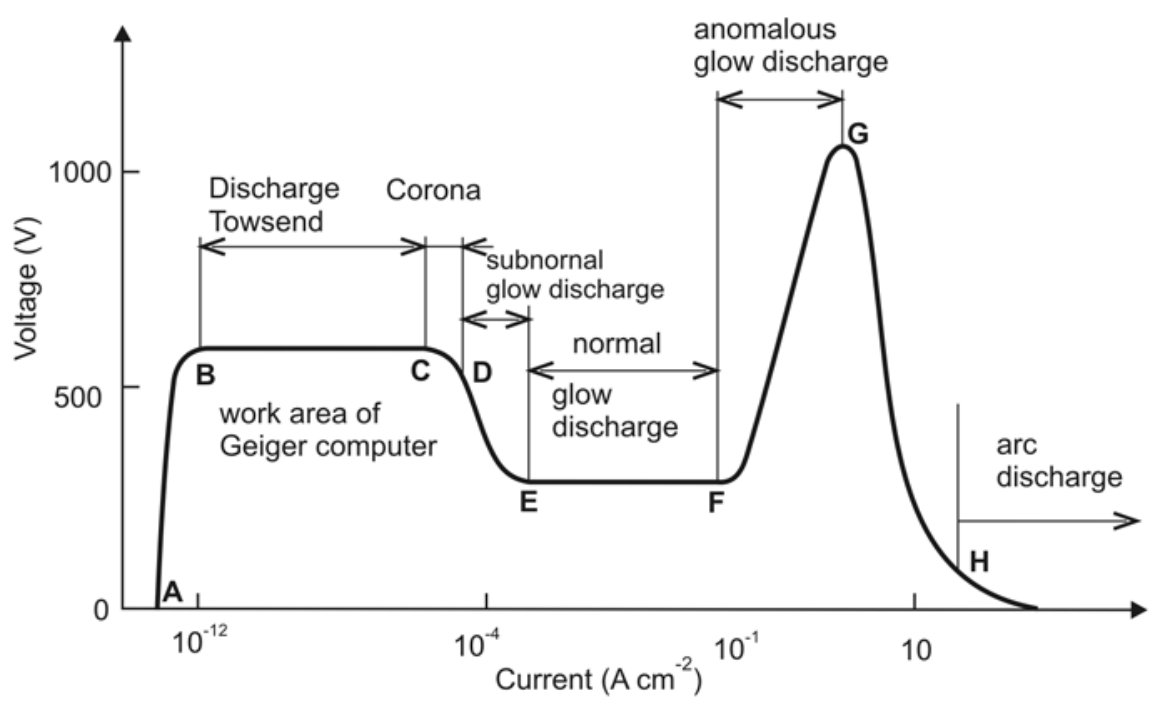

Fig. 4. Anomalous glow discharge [6].

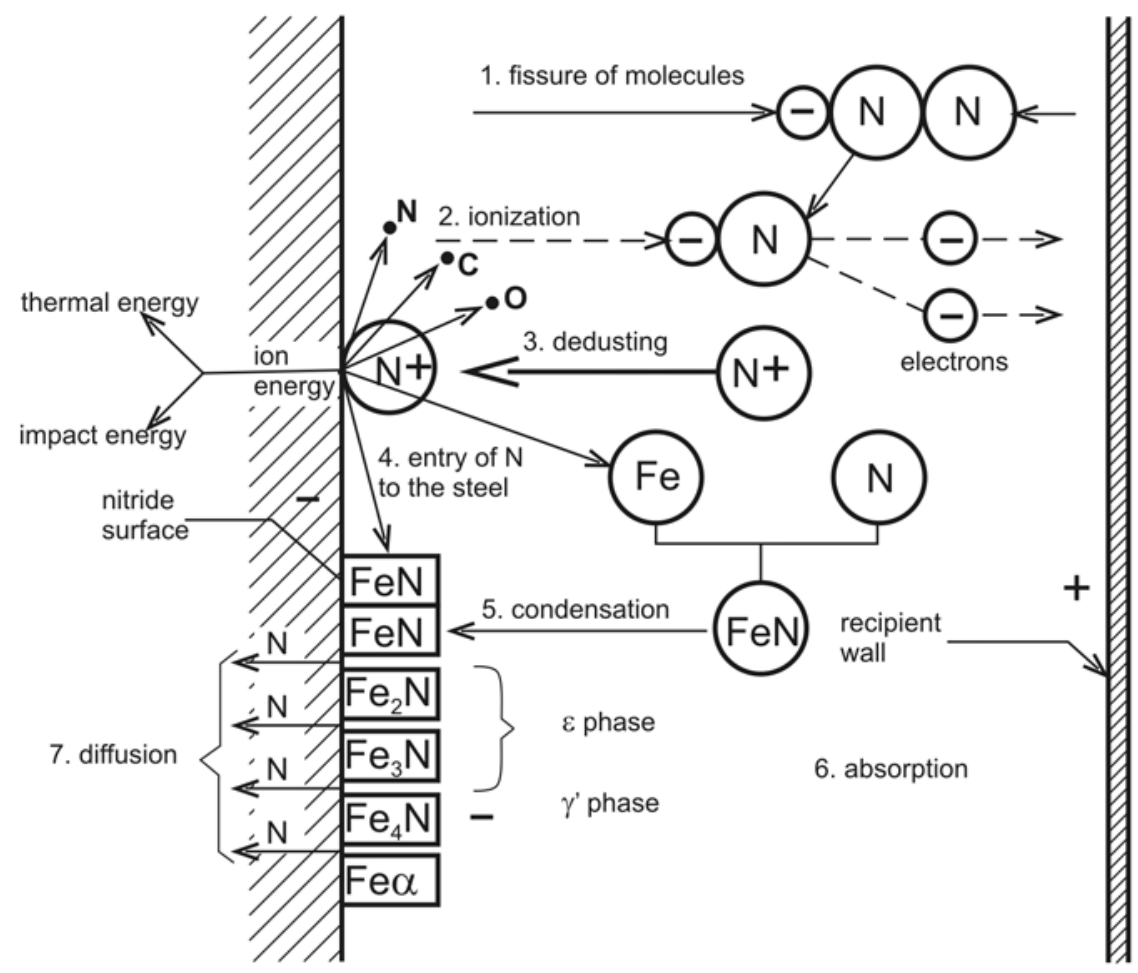

Fig. 5. Plasma nitriding processes [6].

accelerated towards the component surface, impacting on it with high kinetic energy. Part of the incident ions is converted into heat. Ions of iron and alloying elements are knocked out from the surface of the parts. Afterwards, they react further with the atomic nitrogen in plasma. Created nitrides in turn condense on the component surface. After the nitrogen ions impact on the component surface, the adsorbed layer of nitrides with high nitrogen content is created, called $\varepsilon$-phase. The layer containing a major percentage of nitrogen $(8-11.2 \% \mathrm{~N})$ causes its subsequent absorption into the material.

Under the electric field effect, there is huge migration of the working gas molecules. As a consequence of their impact, gas is splitting and ionizing. Positive ions are accelerated towards the cathode, it means towards the surface of nitrided samples [6].

Velocity growth of ions towards the cathode as well 
Ta b le 1. Chemical composition of low-alloyed steel 50CrV4+QT (wt.\%)

\begin{tabular}{cccccccccc}
\hline & $\mathrm{C}$ & $\mathrm{Mn}$ & $\mathrm{Si}$ & $\mathrm{P}$ & $\mathrm{S}$ & $\mathrm{Cr}$ & $\mathrm{Ni}$ & $\mathrm{V}$ & $\mathrm{Cu}$ \\
\hline Standard & $0.46-0.54$ & $0.5-0.8$ & $0.15-0.4$ & $\max .0 .03$ & $\max .0 .03$ & $0.8-1.1$ & max. 0.4 & $0.1-0.2$ & max. 0.25 \\
Analysis & 0.49 & 0.54 & 0.19 & 0.023 & 0.017 & 1.02 & 0.06 & 0.11 & 0.13 \\
\hline
\end{tabular}

as their kinetic energy growth are not linear. Abrupt growth is observed in the close proximity of the nitrided surface within the cathode voltage loss. Consequently, the highest intensity of processes proceeding in anomalous discharge glow is concentrated to a narrow band around the components without respect to their shape and distance from the recipient body - anode (Fig. 5). Molecules splitting and atom ionization are carried out within this band preferentially. Anomalous glow discharge is planar and its luminescent corona copies the component surface. This is very important feature which is essential for using of discharge glow for the diffusion heat treatment.

Component surfaces have to be pure, dry and without passivative layers, e.g. oxides layer. Plasma nitriding allows affiliating the step called cleaning in plasma into the nitriding process. It is the process within which ineligible surface oxides are de-dusted by the instrumentality of accelerated atoms [6].

Plasma nitriding process can be divided into following steps:

1. Induction heating by recipient body at the temperature for cleaning in plasma (lower than nitriding temperature).

2. Cleaning in plasma (de-dusting) - with or without it.

3. Additional heating at the nitriding temperature.

4. Abidance in nitriding temperature during nitriding process.

5. Cooling of the components after nitriding process.

Advantages of plasma nitriding [7]:

- High variability of process parameters which enables either the balanced and porousless white layers or elimination of their formation.

- Growth rate of plasma nitride layers is $30-40 \%$ higher in comparison with the common methods.

- Low nitriding temperatures together with adequate nitriding depth.

- Economic efficiency in comparison to the nitriding in gas (20 times less costs for gas consumption).

- Lower expenses for device maintenance.

Disadvantages of plasma nitriding [7]:

- High acquisition costs and low usage of inside space.

- Necessity of careful material setting and treatment of material with the same chemical composition.

- Nitriding in holes is difficult, it is impossible to form the nitriding layer in small holes. In case of bigger
Table 2. Mechanical properties of low-alloyed steel $50 \mathrm{CrV} 4+\mathrm{QT}$

\begin{tabular}{lc}
\hline Yield strength $R_{\mathrm{p} 0.2}(\mathrm{MPa})$ & 900 \\
Tensile strength $R_{\mathrm{m}}(\mathrm{MPa})$ & $1100-1300$ \\
Elongation $A_{5}(\%)$ & 9 \\
Contraction $Z(\%)$ & 40 \\
Notch impact strength $\mathrm{KCV}\left(\mathrm{J} \mathrm{cm}^{-2}\right)$ & 35 \\
Fatigue limit $\sigma_{\mathrm{c}}$ for a rotating beam & $410-450$ \\
fatigue $(\mathrm{MPa})$ &
\end{tabular}

Table 3. Heat treatment of steel 50CrV4

\begin{tabular}{lcl}
\hline Process & Temperature $\left({ }^{\circ} \mathrm{C}\right)$ & Cooling \\
\hline Quenching & $820-860$ & oil \\
Tempering & 550 & air \\
\hline
\end{tabular}

holes, it is necessary to use additional electrodes.

\section{Experimental material}

As an experimental material, steel $50 \mathrm{CrV} 4$ was used in accordance with Standard EN 89-71, equal to Slovak steel 15 260, Slovak Standard STN 41 5260 [8]. According to the other Standards: 1.8159 (W.Nr.), 6150 (AS 1444-86), Gr.6150 (ASTM A32282), 50ChFA (GOST 14959-79).

Chemical composition of experimental material as well as mechanical properties are shown in Tables 1 and 2 .

The low-alloyed (manganese-chromium-vanadium) steel is commonly used after heat treatment - quenching and tempering - $\mathrm{QT}(.7)$. Optimal diameter for this heat treatment is $80 \mathrm{~mm}$. Welding of steel is difficult. Hot shaping is good. Machining after soft annealing is good. This steel is widely used for highly loaded machines and parts of road vehicles: crankshafts of diesel engines, shafts of driving gears, connecting shafts, pins, springs, axle shafts and piston rods. Steel is suitable for quenching and tempering and contains chemical elements which predetermine it to the chemical - thermal treatment, plasma nitriding.

Parameters of heat treatment are presented in Table 3. 


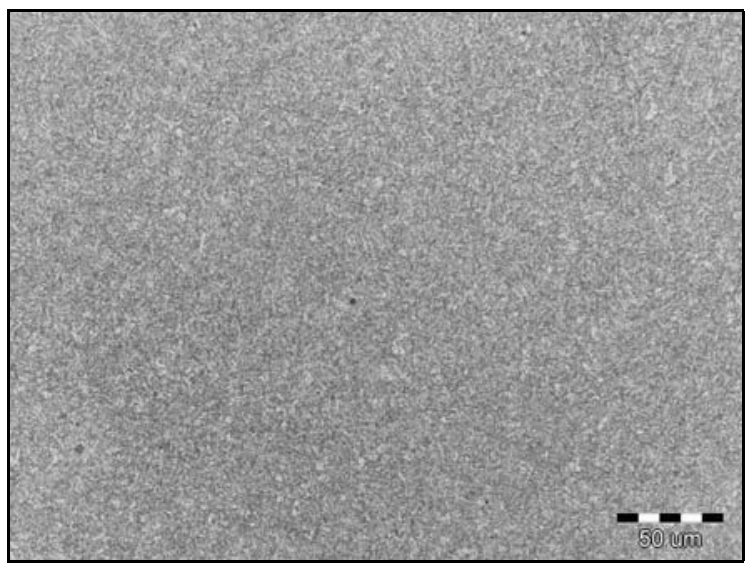

Fig. 6. Microstructure of low-alloyed steel $50 \mathrm{CrV} 4+\mathrm{QT}$, magnified $500 \times$, etch. $2 \%$ Nital.

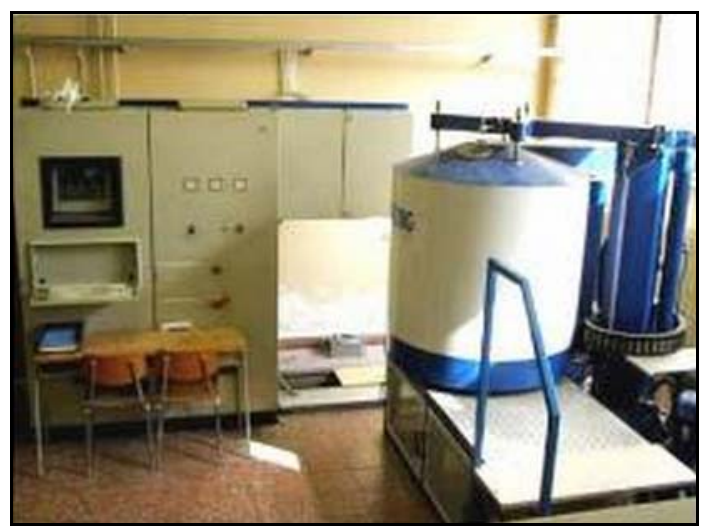

Fig. 7. Nitriding device RÜBIG PN 60/60.

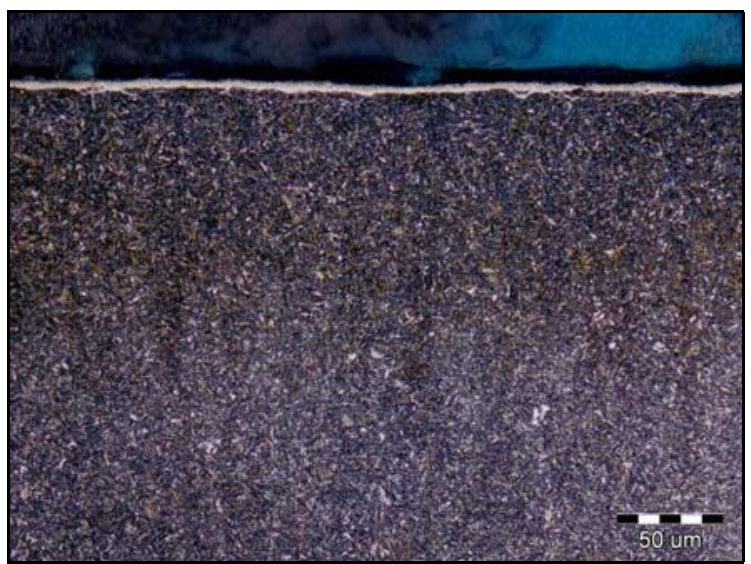

Fig. 8. Microstructure of steel $50 \mathrm{CrV} 4+\mathrm{QT}$ after plasma nitriding, magnified $500 \times$, etch. $2 \%$ Nital.

Microstructure of experimental material $50 \mathrm{CrV} 4+$ QT was observed on metallographic samples by using

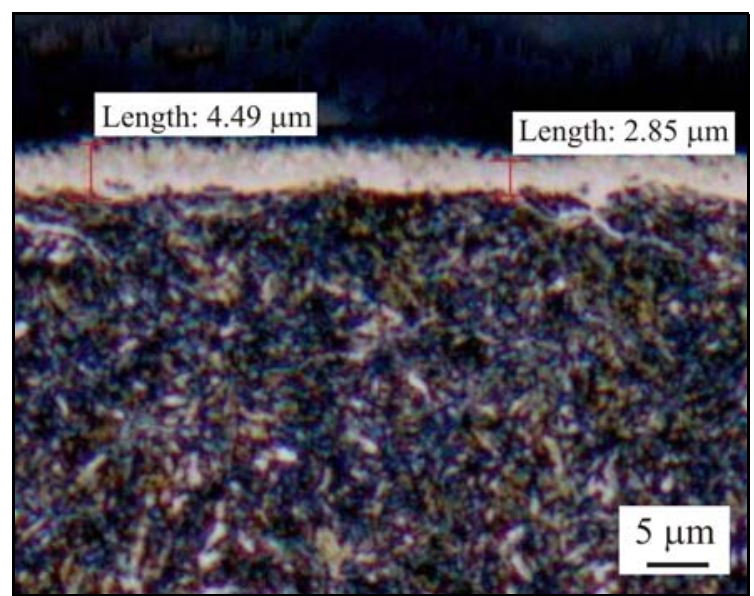

Fig. 9. Detail of white layer width, steel 50CrV4+QT, magnified $2500 \times$, etch. $2 \%$ Nital.

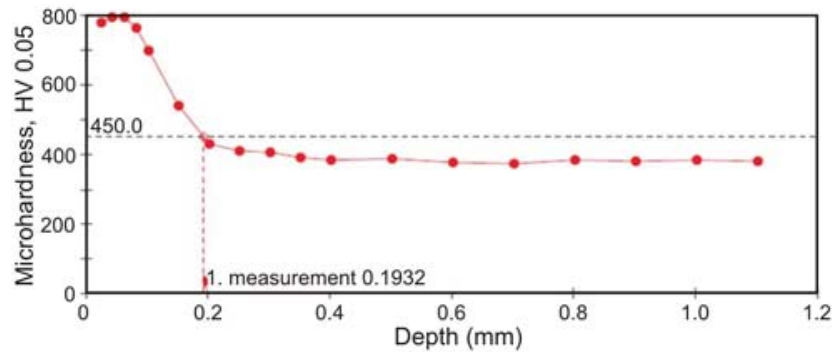

Fig. 10. Micro-hardness of 50CrV4+QT after plasma nitriding.

the optic microscope OLYMPUS GX 51 and software ANALYSIS and is depicted in Fig. 6. Microstructure of basic material steel $50 \mathrm{CrV} 4+\mathrm{QT}$ is created by heterogeneous structure formed by fine martensite and retained austenite as well as sorbite.

\section{Plasma nitriding of experimental samples}

Plasma nitriding of low-alloyed steel 50 $\mathrm{CrV} 4+\mathrm{QT}$ was carried out on the nitriding device RÜBIG PN $60 / 60$ (Fig. 7), in possession of the University of Defence in Brno, Czech Republic.

Applied parameters of plasma nitriding are shown in Table 4.

After $5 \mathrm{~h}$, nitriding layer was formed in the surface layer of steel $50 \mathrm{CrV} 4+\mathrm{QT}$ using plasma nitriding. Nitriding layer consists of the white layer and diffusion layer. Structures are shown in Figs. 8 and 9.

Measured value of white layer width was $4.22 \mu \mathrm{m}$ (Fig. 9).

Micro-hardness across the nitriding layer was determined by using Vickers method in accordance with Standard STN EN ISO 6507-1 [9]. According to the 
Ta b le 4. Parameters of plasma nitriding

\begin{tabular}{lcccccc}
\hline & Temperature $\left({ }^{\circ} \mathrm{C}\right)$ & Gases $\mathrm{H}_{2}: \mathrm{N}_{2}(\mathrm{l} / \mathrm{h})$ & Time $(\mathrm{h})$ & Pressure $(\mathrm{Pa})$ & Voltage $(\mathrm{V})$ & Pulse time $(\mu \mathrm{s})$ \\
\hline De-dusting & 480 & $20: 2$ & 0.5 & 80 & 800 & 100 \\
Plasma nitriding & 500 & $24: 8$ & 5 & 280 & 530 & 100 \\
\hline
\end{tabular}

Ta ble 5. Micro-hardness of the core and nitriding layer thickness

\begin{tabular}{lrccc}
\hline & \multicolumn{3}{c}{ Plasma nitriding -5 h } \\
\cline { 2 - 4 } & \multicolumn{2}{c}{ GH HV0.05 } & GH +50 HV0.05 & Nht $(\mathrm{mm})$ \\
\hline \multirow{3}{*}{ Hardness of core } & 390 & 399 & 450 & 0.193 \\
& 413 & 394 & & \\
\hline
\end{tabular}

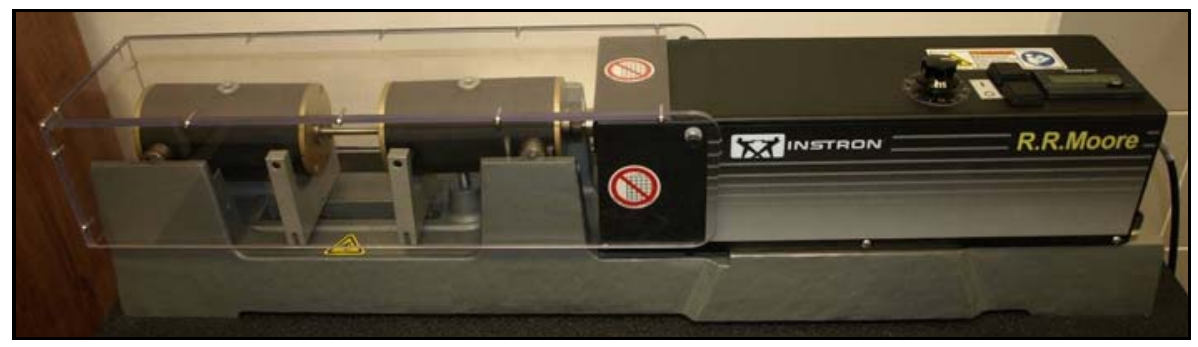

Fig. 11. R. R. Moore model: High speed rotating beam fatigue testing machine, detail of rotating part.

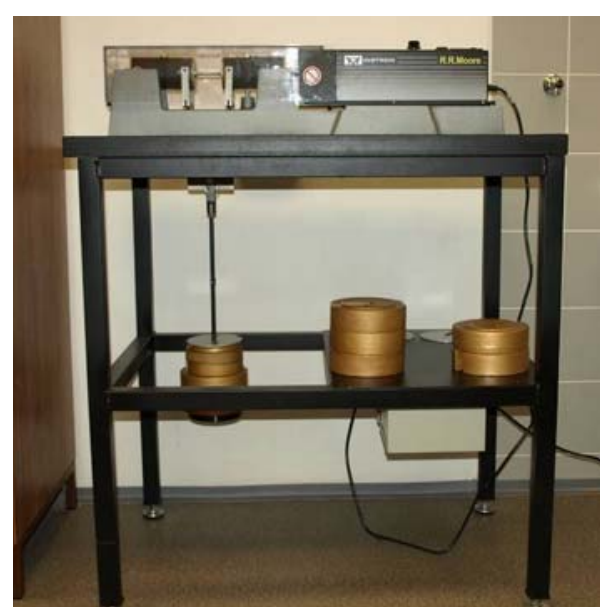

Fig. 12. R. R. Moore model: High speed rotating beam fatigue testing machine, global view.

Standard DIN 50190 [10], the micro-hardness of core GH as well as nitriding layer thickness Nht were determined. As an experimental device LECO ML 247 AT was used. Measured values are shown in Table 5 and depicted in Fig. 10.

Figure 9 shows the detail of measurement of white layer width.

The structure consists of three zones:

- white layer, mixed phases $\varepsilon\left(\mathrm{Fe}_{2-3} \mathrm{~N}\right)$ and $\gamma^{\prime}\left(\mathrm{Fe}_{4} \mathrm{~N}\right)$ of irregular depth ranging from 3 to $5 \mu \mathrm{m}$,

- diffusion layer made up of nitrogen solution in insertion and possibly of the fine nitride precipitates or carbo nitrides,

- structure of tempered martensite resulting from the preliminary heat treatment.

Hardness measurement was carried out in laboratories of University in Trencin using experimental device INSTRON Wolpert Testor. Values of surface hardness of untreated $50 \mathrm{CrV} 4+\mathrm{QT}$ as well as after $5 \mathrm{~h}$ plasma nitriding are shown in Table 6.

\section{Rotating beam fatigue test}

Rotating beam fatigue test was carried out in the Laboratory of mechanical tests at the University of Defence in Brno, Czech Republic, using the experimental device INSTRON R. R. Moore (Figs. 11, 12) in accordance with the Standard STN 420362 [11].

As testing bars, the smooth samples without notch loaded by rotating beam fatigue were used. Shape and dimensions of samples (Fig. 13) were made in accordance with the experimental device producer instructions and depended on the applied loading. In accordance to the requirements, the experimental samples were grinded and polished for roughness $R a \leq 0.4 \mu \mathrm{m}$.

The results of rotating beam fatigue tests on the 
Ta b l e 6. Surface hardness of untreated 50CrV4+QT and after plasma nitriding

\begin{tabular}{lcrc}
\hline State & HV1 & HV5 & HV10 \\
\hline untreated & 603 & 442 & 446 \\
nitrided & 887 & 1022 & 945 \\
\hline
\end{tabular}

Table 7 . Fatigue limits at $1.10^{7}$ cycles

\begin{tabular}{lc}
\hline State & $\begin{array}{c}\sigma_{\mathrm{c}} \text { at } 1 \times 10^{7}(\mathrm{MPa}), \\
n=9250 \mathrm{rpm}=>f=154 \mathrm{~Hz}\end{array}$ \\
\hline untreated & 450 \\
nitrided & 650 \\
\hline
\end{tabular}

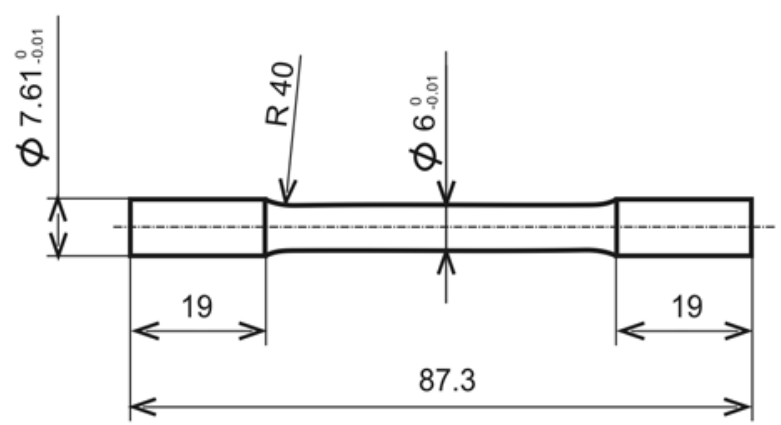

Fig. 13. Shape and dimensions of experimental bars.

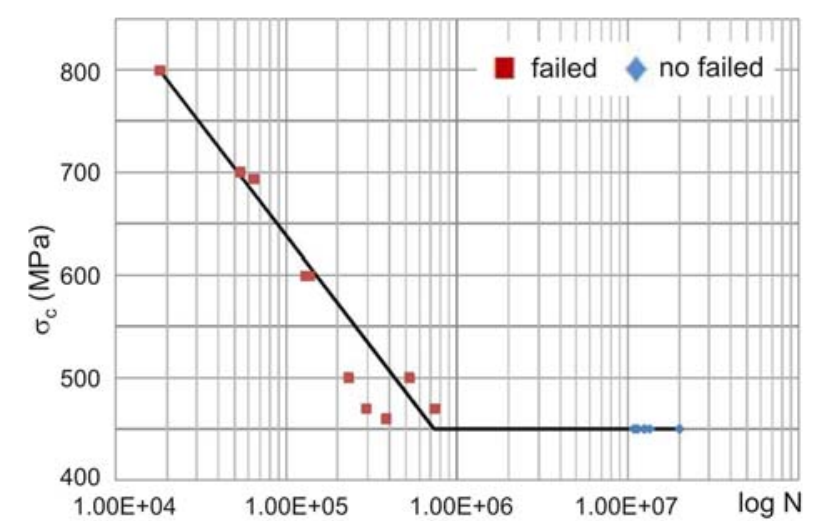

Fig. 14. Wöhler graph of experimental material 50CrV4+ QT.

smooth samples are presented in the Wöhler graphs (Figs. 14, 15) revealing the dispersions which became more significant as the stress amplitudes became low $[12]$.

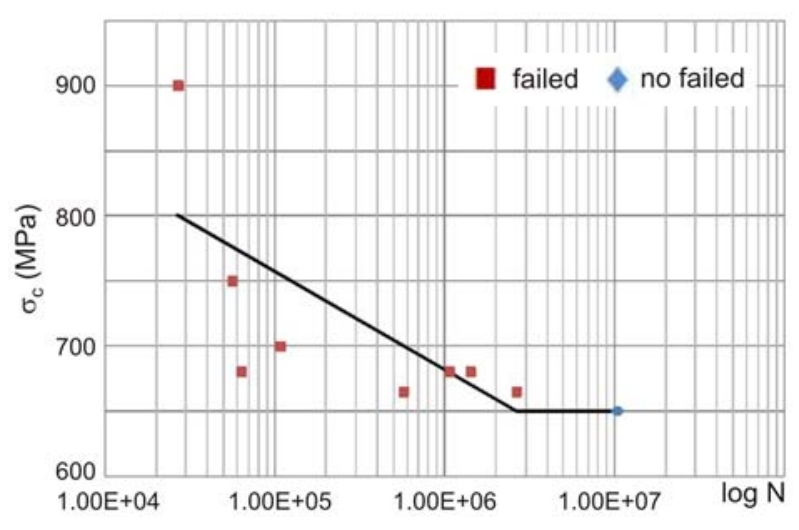

Fig. 15. Wöhler graph of experimental material after $5 \mathrm{~h}$ plasma nitriding.

These dispersions are more remarkable in the case of the nitrided samples within the lower loading high cycle fatigue. This proves the prediction that plasma nitriding improves the fatigue endurance with high number of cycles. The fatigue limits at $1 \times 10^{7}$ cycles, determined by the staircase method are shown in Table 7.

\section{Discussion of results}

Low-alloyed steel 50CrV4 has relatively higher content of chromium (Table 1) which leads to a better aptitude for nitriding. The plasma nitriding ensured a hardened layer of $193 \mu \mathrm{m}$ in depth (Figs. 8, 9) which is composed of two layers:

- White layer, considered for its good tribological properties, must have reduced depth when the treated part is exposed to surface fatigue. This thickness being controlled by the process parameters (Table 4), decreases when the temperature and/or the duration period and/or the nitrogen potential decrease. The white layer is very thin, its thickness is $4.22 \mu \mathrm{m}$.

- Diffusion layer is considered as favourable for the fatigue endurance and thickness of some tenth of millimetres where the nitrogen is inserted as a solid solution in the shape of carbo nitride or nitride precipitate. The solid solution effect and precipitation of chromium nitrides induce coherent distortions and expansion of the matrix, by increase in volume, causing significant hardening (Table 6).

Fatigue lifetime is normally improved by increasing the surface hardness with a surface treatment. Vickers micro-hardness was evaluated across the nitrided samples (Table 5, Fig. 10). Comparison of hardness of untreated and treated samples is shown in Table 6 and presents the increase of $47 \%$ (HV1), $131 \%$ (HV5) and $111 \%$ (HV10). Two series of rotating beam fatigue tests were carried out. Applied stress was in the range from $900 \mathrm{MPa}$ to $450 \mathrm{MPa}$. Number of cycles 
was within $1 \times 10^{4}$ to $1 \times 10^{7}$ cycles. The results are plotted in Figs. 14 and 15 for untreated and nitride samples. The fatigue limits shown in Table 7 present the increase of fatigue limit of $44 \%$ in case of nitride samples.

\section{Conclusions}

In this paper the effect of plasma nitriding on the fatigue limit was analyzed. The main results can be summarized as follows:

- Plasma nitriding $\left(500^{\circ} \mathrm{C}, 5 \mathrm{~h}\right)$ led to the formation of white layer $\left(\varepsilon+\gamma^{\prime}\right)$ and diffusion layer with thickness equal to $193 \mu \mathrm{m}$.

- Fatigue resistance improvement was proved by an increase of fatigue limit, $450 \mathrm{MPa}$ for untreated material and $650 \mathrm{MPa}$ for nitride material.

- The positive effect of plasma nitriding on fatigue resistance of low-alloy steel $50 \mathrm{CrV} 4$ was in good harmony with plasma nitriding of similar steels presented in works $[13-15]$.

\section{Acknowledgements}

This publication was created in the frame of the project "Alexander Dubček University of Trenčín wants to offer high-quality and modern education", ITMS code 26110230099, based on the Operational Programme Education.

Modern Education for Knowledge Society. The project is co-funded by the European Social Fund.

\section{References}

[1] Hrubý, V., Lipták, P., Pokorný, Z.: Plasma Nitriding of Cavities. Rzeszów, RSdruk 2013. ISBN 978-83-6366693-4.

[2] Hrubý, V., Kadlec, J.: Surface Technologies. Brno, VAAZ 1997. (in Czech)

[3] Jurči, P.: In: Proceedings of Metal 2009. Ostrava, TANGER, spol. s r. o. 2009. ISBN 978-80-87294-03-1.

[4] Pye, D.: Practical Nitriding and Feritic Nitrocarburizing. 2nd Edition. Materials Park, ASM International 2003. ISBN 0-87170-791-8.

[5] Hrubý, V.: Study Nitriding Glow Discharge in Ionized Environments. [Ph.D. Thesis]. Brno, VAAZ 1984. (in Czech)

[6] Holemář, A., Hrubý, V.: Ion Nitriding in Practice. Praha, SNTL 1989. (in Czech)

[7] Hrubý, V., Kusmič, D.: In: Proceedings of Control Technology and Advanced Thermal Processing Equipment. Praha, Asociace pro tepelné zpracování kovů 2005, p. 23. ISBN 80-239-5503-9. (in Czech)

[8] STN 41 5260: Steel 15260: Mn-Cr-V. 1989. (in Slovak).

[9] STN EN ISO 6507-1: Metallic Materials. Vickers Hardness Test. 2005. (in Slovak)

[10] DIN 50190-3: Hardness Depth of Heat-Treated Parts: Determination of the Diffusion Hardening Depth and the Diffusion Depth. 1999.

[11] STN 42 0363: Testing of Metals - Fatigue Tests (in Slovak).

[12] Ličková, M., Barényi, I.: Material Science I - Lecture Book. 1st Edition. Trenčín, FŠT TnUAD 2009. ISBN 978-80-807-5435-80. (in Slovak)

[13] Zhou, Ch., Wang, M., Dong. H., Wang, L., Wu, R.: Materials and Design, 46, 2013, p. 539. doi:10.1016/j.matdes.2012.08.061

[14] Terres, M. A., Ben Mohamed, S., Sidhom, H.: International Journal of Fatigue, 32, 2010, p. 1795. doi:10.1016/i.ijfatigue.2010.04.004

[15] Sirin, S. Y., Sirin, K., Kaluc, E.: Mater Charact, 59, 2008, p. 351. doi:10.1016/i.matchar.2007.01.019 